\title{
CONTRIBUCIONES DE MERLEAU-PONTY A LA FILOSOFÍA FEMINISTA
}

\author{
$M^{a}$ Carmen López Sáenz \\ Universidad Nacional de Educación a Distancia
}

El año 2008 celebramos el centenario del nacimiento de Merleau-Ponty (1908-1961) y el de Simone de Beauvoir (1908-1986), fenomenólogos de la existencia y colaboradores ambos. La autora de Le deuxième sexe, en coherencia con la máxima del existencialismo, declaraba que la mujer no nace como tal, sino que se hace y que la identidad corporal genérica de las mujeres responde a un estilo aprendido a lo largo de sus vidas; ' no consiste, por tanto, en una esencia inmutable, sino que se define fenomenológicamente como un proceso histórico y existencial. De este modo, evitaba los esencialismos que reducen lo femenino a una entidad dada de una vez para siempre. A pesar de ello, para Beauvoir, como para Merleau-Ponty, el género que se iba adquiriendo no era una cualidad secundaria, independiente de la materialidad concreta del cuerpo, sino una encarnación de signo cultural. ${ }^{2}$ Para describirla, Beauvoir estudió, como buena fenomenóloga de la existencia, la experiencia vivida desde la situación femenina.

Siguiendo estrechamente a su coetáneo, analizará la diferencia sexual tomando el cuerpo como sujeto de experiencia y no como objeto científico, adhiriéndose así a la consideración merleau-pontiana del cuerpo vivido como nuestra situación y horizonte desde el que las percepciones se destacan, impactada por la admiración que causaron en el filósofo los manuscritos husserlianos sobre el Leib y la conciencia interna del tiempo.

1 Cr. Beauvoir, de S. de, Le detuiéme sexe, vol. II. Paris: Gallimard, 1949 p. 34.

${ }^{2}$ Cf. Bcauvoir, de S. de op. cit., p. 66. Tambićn en Beauvoir, de S. de, La force de l'áge. Paris: Gallimard, 1995 , p. 231. Sobre la relación del pensamiento de Beauvoir con Merleau-Ponty, pero también con otros fenomenóløgos como Husserl y Lévinas, cf. Heinămaa, S., Toward a Phenomenology of Sexual Difference. Husserl, Merleau-Ponty and Beauvoir: Maryland: Rowman, 2002. 
Desde estas premisas, no se puede decir, como algunas interpretaciones actuales han destacado, que Beauvoir presente el cuerpo femenino tan sólo como un obstáculo para la auto-realización de la mujer y que esto se deba a su deuda con el voluntarismo de la subjetividad sartreana y con el cartesianismo que continúa objetivándolo. Ciertamente, desde una perspectiva exclusivamente sartreana, es imposible comprender las experiencias propiamente femeninas, porque éstas no son vividas por las mujeres ni como instrumentos ni como obstáculos para sus proyectos. Beauvoir no parece participar de esta visión dicotómica e instrumental cuando se detiene en la maternidad, en la menopausia y en otras muchas experiencias de la corporeidad femenina, oponiéndose así al feminismo que hace abstracción de la misma. Como Merleau-Ponty, Beauvoir es consciente de que la existencia tiene una dimensión corporal que está implicada en nuestras relaciones con los otros y con el mundo.

Como es sabido, Beauvoir reseñó la Fenomenología de la percepción valorando su concepción concreta del sujeto como conciencia encarnada. ${ }^{3}$ La lectura de esta obra permite describir las experiencias femeninas sin hacerlo desde un punto de vista masculino objetivante, entendiéndolas como descentramientos de la subjetividad o como aperturas a lo otro desde sí, porque Merleau-Ponty concede estatuto filosófiço al cuerpo, ${ }^{4}$ lo entiende fenoménicamente y no de manera objetivista. Se concentra en el cuerpo vivido, en esa figura que se destaca de una corporalidad anónima que nos envuelve por todas partes y nos enlaza con lo otro en virtud del esquema corporal, concebido como "postura orientada hacia determinada tarea actual o posible",, como matriz de habitualidades que, antes que un conocimiento discursivo, nos proporciona un saber práctico.

Como es sabido, Beauvoir reseñó la Fenomenología de la percepción valorando su concepción concreta del sujeto como conciencia encarnada. La lectura de esta obra permite describir las experiencias femeninas sin hacerlo desde un punto de vista masculino objetivante, entendiéndolas como descentramientos de la subjetividad o como aperturas a lo otro desde sí, porque Merleau-Ponty concede estatuto filosófico al cuerpo, lo entiende fenoménicamente y no de manera objetivista. Se concentra en el cuerpo vivido, en esa figura que se destaca de una corporalidad anónima que nos envuelve por todas partes y nos enlaza con lo otro en virtud del esquema corporal, concebido como "postura orientada hacia determinada tarea actual o posible", como matriz de habitualidades que, antes que un conocimiento discursivo, nos proporciona un saber práctico.

${ }^{3}$ Beauvoir, de S. de, "La Phénoménologie de la perception de M. Merleau-Ponty", Les Temps Modernes 2 (1945), pp. 363-367.

${ }^{4}$ Un mayor desarrollo de este asunto en López Sáenz, M.C.: "La existencia como corporeidad y carnalidad en la filosofía de M. Merleau-Ponty", en Rivera de Rosales, J./López Sáenz, M.C., (coords.), El cuerpo. Perspectivas filosóficas. Madrid: Estudios UNED, 2002, pp. 179-207.

${ }^{5}$ Merleau-Ponty, M., Phénoménologie de la perception. Paris: Gallimard, 1979, p. 116. 
Toda experiencia es corporal y situada; por ello, no puede considerarse abstractamente. Si ninguna experiencia vivida puede objetivarse, tampoco la del cuerpo propio, porque éste es primariamente apertura y movimiento del yo al otro que revela las cosas como fenómenos. Sin embargo, esa experiencia le ha sido impuesta a la mujer desde fuera, al mismo tiempo que su cuerpo ha sido objetivado, abstraído del verdadero cuerpo fenoménico y reducido a sus funciones biológicas. En otras palabras, la mujer ha sido suprimida como cuerpo-sujeto, es decir, como fuente de deseos y clave del Ser Vertical en el mundo. Ha quedado reducida a pura presencia ante el logos dominante masculino por la cultura del consumo que sublima la exterioridad corporal. Esa dominación cultural identifica a la mujer con su cuerpo-objeto y paradójicamente le niega la capacidad de ejercer un control moral sobre su cuerpo. Así se posiciona a la mujer corporalmente en sí, más que para sí, se anula su libertad y se la confina en la inmanencia. De este modo, se justifica su exclusión de una racionalidad completa y de toda trascendencia, incluida la de su cuerpo objetivado. Merleau-Ponty reacciona contra esta desviación del verdadero ser subjetivo-objetivo del cuerpo propio proponiendo la vivencia vertical del mismo, que actúa como origen inmanente de todas las trascendencias. Esta verticalidad o "Ser salvaje", ${ }^{6}$ anterior a las diferenciaciones en componentes opuestos, ha de entenderse como profundidad en ejercicio o como una suerte de orientación lineal dinámica hacia la raíz que excluye la distanciación horizontal y la perspectiva que le es inherente. Su modo de ser, por el contrario, es el erigido en y no el postrado frente $a$.

El concepto de cuerpo de Merleau-Ponty, como algo que no está fijado biológicamente, ayuda, además, a replantear el problema del género haciéndonos tomar conciencia de la importancia de lo corporal para comprender y rehacer las diversas maneras de dar sentido al mundo, de re-configurar significaciones, hábitos y actitudes heredados y construidos.

Una vez que el feminismo nos ha ayudado a ver que el modo de ser universalmente asumido es el masculino y que las mujeres vivimos en el seno de instituciones que transmiten patrones masculinos y hasta machistas de corporalidad, necesitamos encontrar por nosotras mismas y desarrollar otros modos más apropiados para nuestro ser corporal sin absolutizarlos, ya que como dice A. Valcárcel, "mientras los cuerpos de las mujeres sigan sobre-significados, e hipernormados existirá un sobreesfuerzo de presentación del yo correspondiéndose con una marca de genericidad potencialmente ahogadora de ese yo"; 7 por eso, es preciso reconceptualizar el cuerpo para vivirlo al margen del dualismo clásico que lo distancia del espíritu y de la situación en la que se inscribe, afrontarlo como cuerpo fenoménico, no sólo como Körper y adscribirlo a todo ser-en-el-mundo, no sólo a la mujer. 
En otros trabajos, hemos considerado la fenomenología de M. MerleauPonty como correctivo a la tendencia postmoderna que hace del cuerpo un simple producto sociocultural y del género un mero artificio, porque comprende el cuerpo propio como el punto cero abierto a múltiples variaciones, lo que le permite réconfigurar las significaciones recibidas, la propia imagen corporal y las actitudes hacia el mundo. Estas capacidades tienen importantes repercusiones para el feminismo, porque implican que es posible transformar lo que nos rodea y sus interpretaciones mediante los comportamientos individuales y colectivos, frente al postestructuralismo que sólo acepta la posibilidad de diferentes modos discursivos de socialización que nos determinan por completo. Las virtualidades corporales y conductuales exigen reconsiderar el cuerpo como sujeto-objeto, como quiasmo entre naturaleza y cultura para evadir la tradición dualista que únicamente lo piensa como impedimento para razonar. De ahí se ha seguido nuestra propuesta de otra razón encarnada, más amplia que la razón dominante que ha acabado instrumentalizando todo lo no cuantificable, una razón que se va haciendo histórica e interpretativamente y que se amplía hasta incorporar las voces y deseos de libertad de las mujeres. ${ }^{8}$ Esta razón que también siente y crea no es meramente discursiva, sino también experiencial y situada. Por ello, consideramos que la importancia que la fenomenología otorga a la experiencia vivida carnalmente debe continuarse, en contra de las posiciones postestructuralistas que le niegan valor cognoscitivo para concedérselo al lenguaje y a la textualidad.

Aunque la fenomenología no desconoce la interacción entre experiencia y lenguaje, no absolutiza la experiencia lingüística, sino que la refunda en otras más originarias y muestra que el lenguaje hablante tiene un componente gestual originario. ${ }^{9}$ Concretamente, en Merleau-Ponty la experiencia siempre es carnal y hasta el lenguaje proviene de ella, porque no es ni algo puramente externo, ni algo predeterminado por la práctica lingüística e hipostasiado después.

La corporeidad merleau-pontiana es un desafío a las teorías del discurso que consideran el lenguaje como un mero sistema de signos y convierten al sujeto en uno de sus productos. El cuerpo vivido es una instancia pre-discursiva y determina, aunque no completamente, nuestra identidad tanto como nuestra diversidad siempre en interacción con el mundo y los otros. El sujeto corporal es, como dice el fenomenólogo, "una diferencia sin contradicción, esa divergencia (écart) entre el adentro y el afuera que constituye su secreto natal". ${ }^{10}$ Esto quiere decir que en la misma constitución carnal se encuentra ya cierta articulación

8 Véase mi trabajo, "Feminismo y racionalidad ampliada, Contrastes. Revista Internacional de Filosofia VIII (2003), pp. 93-107.

9 Véase mi estudio, "La Parole as a Gesture of the Originating Differentiation", en Penas, B./ López Sáenz, M.C. (eds.), Interculturalism. Between Identity and Diversity. New York/Berna: Peter Lang, 2006, pp. 27-46.

${ }^{10}$ Merleau-Ponty, M., La Nature. Paris: Seuil, 1995, pp. 135-6. 
de identidad y diferencia. El hecho de que nuestra situación corporal nunca esté concluida impide que se reconcilie completamente con nuestra identidad; más bien nos recuerda nuestra vulnerabilidad al mismo tiempo que nos hace percatarnos de que la corporalidad es la apertura primigenia, la condición finita que nos abre a lo infinito, la trascendencia en la inmanencia.

La experiencia vivida corporalmente no puede reducirse a una narración de sus efectos discursivos, sino que requiere descripciones fenomenológicas, tanto del acontecimiento en el que aquélla tiene lugar, como de las retenciones y protenciones que provoca en nuestra experiencia sedimentada. Hacer visible ésta, sin menosprecio de su crítica, es anunciar la posibilidad de su transformación, así como la de su influencia en la acción que desencadena y que se funda en estructuras de experiencia preconceptuales que quedan inscritas en la situación corporal. Así es como la fenomenología puede ayudar a comprender la experiencia vivida por las mujeres y su relación con el feminismo. ${ }^{11}$

Considerar fenomenológicamente la experiencia propia no es, sin embargo, un ejercicio solipsista, sino tomarla como coextensiva con todo ser del que podamos tener alguna noción, ${ }^{12}$ porque la experienciạ es relacional y sólo ella nos permite acceder a lo común: "no alcanzamos el universal desprendiéndonos de nuestra particularidad, sino convirtiéndolo en un medio para alcanzar a los otros, en virtud de esa afinidad misteriosa que hace que las situaciones se comprendan entre ellas". ${ }^{13}$ A lo universal no se llega eliminando a los individuos y sus diferencias (incluidas las diferencias sexuales y las genéricas ${ }^{14}$ ), sino reactivándolas críticamente desde nuestra propia estilización de lo sedimentado, hasta conseguir que la propia vida aparezca ante sí "como absolutamente individual y absolutamente universal" 15 o como el fruto de la decisión tomada por alguien acerca de algo que le ha sido legado.

La fenomenología existencial de Merleau-Ponty ayuda al feminismo, redefiniendo de esta manera dialéctica la universalidad y la singularidad, rompiendo con la concepción de un sujeto dominante enfrentado a objetos a los que dominar. Las interrelaciones entre ambos definen a la conciencia carnal de la vida. Ésta comienza rechazando el solipsimo, la dominación y aceptando la

11 Así lo ha comprendido, por ejemplo, Nussbaum, M., "Feminism and Philosophy", New York Review of Books, October 20, 1994, pp. 59-63.

12 Cf. Merleau-Ponty, M., Sens et non-sens. Paris: Gallimard, 1966, p. 114.

13 Ibid., p. 113.

14 Conviene recordar que, en su persecución de la igualdad, el feminismo no aboga por la eliminación de las diferencias, sino por la supresión de la discriminación en razón de las mismas. Sobre el sentido y las posibilidades de esa nueva concepción de lo universal, véase López Sáenz, M.C., "De la expresividad al habla. Un modelo diacrítico de interculturalidad", en López Sáenz, M.C./Penas, B. (eds.), Paradojas de la Interculturalidad. Filosofia, lenguaje y discurso. Madrid: Editorial Biblioteca Nueva, 2008, pp. 31-61, e "Identidad lateral. Un concepto de la fenomenología", Berceo 153 (2007), pp. 97-129.

15 Merleau-Ponty, M., op. cit., p. 115. 
coexistencia intercorporal. La reafirmación de la encarnación de la conciencia en el cuerpo y en el mundo compartido no implica, sin embargo, la desaparición del yo, sino la toma de conciencia de su constitución inacabada a través de procesos de apropiaciones y desapropiaciones que conducen a la identidad de un yo ampliado o "descentrado", en tanto reorganización perceptiva vivida del campo de experiencias. Dicho campo no está polarizado, sino que es el proceso de ser-coexistiendo en el cual se producen múltiples diferenciaciones. Desde esta nueva comprensión de la subjetividad, es posible aceptar una cierta identidad femenina que se va configurando en las relaciones que mantiene con su propio ser corporal y con sus múltiples modos de ser y de actuar en situaciones que comparte con otros y otras.

Por lo que llevamos dicho, no es de extrañar que Merleau-Ponty haya influido decisivamente en el "feminismo corporal", nacido en los años 90, que considera la corporalidad como un hecho central para la experiencia ${ }^{16} \mathrm{y}$ critica el predominio patriarcal de la racionalidad ${ }^{17}$ y la conciencia, así como la dicotomía cuerpo-espíritu, con la consiguiente subordinación del primero al segundo y la asociación del cuerpo con la mujer y del espíritu con el hombre. Estos reduccionismos no dan cuenta de la verdadera realidad, de lo que realmente hay: "un cuerpo del espíritu y un espíritu del cuerpo y un quiasmo entre ellos". ${ }^{18}$

El quiasmo no excluye la racionalidad; la fenomenología merleau-pontiana no renuncia a ella, pero, frente a la racionalidad dominante, sesgada y artificiosa, plasmada en un estilo generalizado de pensamiento fragmentario y abstracto que pierde de vista la rica unidad de la vida y culmina en el cientificismo, reivindica una raison élargie ${ }^{19}$ que se va haciendo y que no sólo tiene implicaciones epistemológicas (de survol), sino existenciales. Esta racionalidad no se resigna a la reducción de sus dimensiones al mero uso instrumental de las mismas y se abre a todo el universo de la aisthesis, ${ }^{20}$ la sensibilidad, las pasiones, los afectos... sin considerarlos meros derivados de las sensaciones representativas, sino, como éstas, presencia al mundo por el cuerpo y "la Razón está también en este horizonte - promiscuidad con el Ser y el mundo". ${ }^{21}$ Naturalmente,

${ }^{16}$ Una compilación de estas recepciones, en Martin Alcoff, L., "Merleau-Ponty and Feminist Theory on Experience", en Evans, F./Lawlor, L. (eds.), Chiasms. Merleau-Ponty's notion of Flesh. New York: State University of New York, 2000; pp. 251-273.

${ }^{17}$ Esta concepción distorsionada de la razón es denominada patriarcal y criticada por Celia Amorós en Hacia una crítica de la razón patriarcal. Barcelona: Anthropos, 1985.

${ }_{18}$ Merleau-Ponty, M., Le Visible et l'Invisible, p. 313.

${ }^{19}$ Merleau-Ponty, M.,: Visible et l'Invisible, p. 292. Véase mi estudio, "Filosofía feminista y crítica de la racionalidad dominante", Investigaciones Fenomenológicas IV (2005), pp. 29-57.

${ }^{20}$ Véase mi trabajo, "El sentido de la Aisthesis en Merleau-Ponty", en Santos, J.M./Alves, P.M.S./Barata, A. (eds.), A Fenomenologia Hoje. Lisboa: Phainomenon/Associação Portuguesa de Filosofia Fenomenológica, 2003, pp. 299-311.

${ }^{21}$ Merleau-Ponty, M., Visible et l'Invisible, p. 292. 
Merleau-Ponty no se refiere a la razón del espectador desinteresado, sino a la del sujeto comprometido carnalmente. Reivindica una razón ampliada a las emociones y a lo sensible para luchar contra la colonización de otras formas de pensar y actuar y contra su estigmatización como irracionales.

Las mujeres no podemos adaptarnos fácilmente a una idea de racionalidad que ha sido secularmente definida por oposición a lo femenino. Esto no constituye, sin embargo, un obstáculo para continuar luchando por la igualdad y el derecho de acceso a los espacios públicos en los que se gesta y distribuye el logos. Ahora bien, esa lucha debe aunarse con la reivindicación de las diferencias, de manera que el objetivo último no sea otro que la redefinición de la razón, que pasa por el reconocimiento de su encarnación, por la crítica de su patriarcalismo y por la ampliación de sus campos. Para ello, la filosofía feminista no ha de contentarse con denunciar las opresiones ejercidas por el grupo dominante en nombre de la Razón, sino que debe reconocer que hombres y mujeres son responsables del estatuto de la racionalidad como ideal universal y debe eliminar los estereotipos impuestos y consentidos. Como la fenomenología nos enseña, la universalidad de esa razón no se impone, sino que se participa de ella sin renunciar a la singularidad y se adquiere en la propia experiencia ampliada y corregida por la del otro, a partir del momento en que aprendemos a ver lo propio como extraño y lo ajeno como algo común. Desde esta convicción, Merleau-Ponty establecerá una universalidad existencial - racionalidad encarnada- cuyo punto de partida será el cuerpo fenoménico como identidad que nos abre a las diferencias. Por otra parte, intentará superar los dualismos clásicos, especialmente el de la naturaleza y la cultura, estrechamente relacionado con la falsa dicotomía entre sensibilidad y racionalidad.

El potencial de la corporalidad proporciona la base para comprender de un modo no reduccionista las relaciones del ser humano con la naturaleza y para hacer del conocimiento y de la razón complementos de la sensibilidad. El cuerpo como integrante del campo perceptivo es naturaleza, pero naturaleza abierta a los encuentros, a las culturas y al mundo. En sus últimas obras, Merleau-Ponty considerará a éste y al cuerpo como modulaciones de la Chair primordial, de manera que "no hay dos naturalezas, la una subordinada a la otra, sino un ser doble", ${ }^{22}$ la carne como ser de dos caras: la carne del cuerpo y la carne del mundo.

22 Merleau-Ponty, M., Résumés de Cours. Collège de France 1952-1960. Paris: Gallimard, 1968, p. 177. He estudiado las implicaciones de la nueva ontología merleau-pontiana en las relaciones entre cultura y naturaleza en "Pensar y sentir la carne del mundo desde la ecofenomenología", en Alves, P.M.S./ Santos, J.M./Sá, A. (Orgs.), Humano e Inhumano. A dignidade do homen e os novos desafios. Lisboa: Centro de Filosofia da Universidade de Lisboa, 2006, pp. 161-189. Véase asimismo, "La carne del mundo. Una contribución de la ecofenomenología a la ecología profunda", Ludus Vitalis XIV (26) (2006), pp. 171-187. 
En contra de la oposición entre la materialidad inerte y la forma que la domina racionalmente y le da inteligibilidad, así como frente a la asociación habitual de la primera con lo femenino y de la segunda con lo masculino, Merleau-Ponty articulará ambos principios, valiéndose de otro más originario: la Carne. Ella conceptualiza lo presuntamente natural otorgándole un rango filosófico, a pesar de la dificultad de definir con los términos tradicionales este concepto que "no tiene nombre en ninguna filosofía", ${ }^{23}$ porque no es materia pasiva determinada por algo externo, sino elemento activo y auto-engendrado. Como la Tierra referencial, la carne del cuerpo y la del mundo actúan de horizonte (Grund) desde el que todo se destaca. Por otro lado, es imposible establecer una división entre lo que hay de natural en el individuo y lo que hay de cultural en él. Los dos órdenes forman parte de un único fenómeno global: ${ }^{24}$ la cultura. Ella promueve relaciones significativas entre los seres gracias al cultivo de lo natural; a su vez, "una naturaleza sin testigos no hubiera sido ni sería". 25

También la mujer, al ocuparse preferentemente de la socialización de lo orgánico, tiende puentes entre la naturaleza y la cultura. Lo habitual es considerar a ésta superior a aquélla, porque encarna el logos masculino. La dialéctica de la Ilustración ha mostrado, sin embargo, que éste acaba deviniendo razón estratégica que termina desencantando al mundo y subyugando a la naturaleza. El interés de domino se extiende así también a la mujer y aboca a la unidimensionalidad. La necesaria descolonización del mundo de la vida pasa por la crítica de la entronización de esa razón que, en Merleau-Ponty, como hemos visto, toma la forma de la reivindicación de una racionalidad más comprehensiva.

El pensamiento tradicional instauró la polarización que identificaba a la mujer con la naturaleza, y subordinaba a ésta a la cultura que la domesticaba. El feminismo lucha contra esta adscripción reivindicando la feminización del hombre y la valoración cultural de las potencialidades femeninas. El reconocimiento y la universalización de las tareas vitales devaluadas y atribuidas a la mujer permitirán superar los dualismos clásicos (razón/emoción, pasividad/actividad, público/privado, social/individual, etc.) y comprender el valor de la naturaleza por sí misma. En trabajos previos, hemos justificado, desde estas y otras premisas, la aplicación de la fenomenología existencial merleau-pontiana al ecofeminismo. ${ }^{26}$

La lucha merleau-pontiana contra los dualismos, que contribuye a una ontología no reduccionista y a una filosofía no logocéntrica, ha sido bien acogida por las feministas de la diferencia, pero debería contribuir también al

${ }^{23}$ Merleau-Ponty, M., Le Visible et l'Invisible, p. 193.

${ }^{24}$ Cf. Merleau-Ponty, M., Les relations avec auttrui chez l'enfant. Paris: CDU, 1951, p. 13.

25 Merleau-Ponty, M., Résumés de Cours. Collège de France 1952-1960, p. 95.

${ }^{26}$ Así lo hemos hecho en "La continuidad del ecofeminismo con la filosofía de M. MerleauPonty", Cavana, L./Puleo, A.H./Segura, C. (coords.), Mujeres y ecología. Historia, Pensamiento y sociedad. Madrid: Almudayna, Col. Laya, 2004, pp. 213-225. 
feminismo de la igualdad y a su crítica de la razón patriarcal abstraída del cuerpo y de las sedimentaciones e intencionalidades horizónticas de las que provienen motivaciones y afecciones. ${ }^{27}$ Todos estos estratos configuran la experiencia pre-reflexiva, la cual, junto con el significado pre-lingüístico que envuelve todo sentido, es objeto del interés merleau-pontiano. Tener en cuenta esta dimensión es tomar conciencia de que no sólo hay poderes lingüísticos y discursivos, sino también determinaciones sociales, económicas, políticas (explicitadas o no) y hasta otras que proceden del inconsciente.

Éstas y otras reivindicaciones comunes no eximen, sin embargo, de crítica a Merleau-Ponty por parte de las feministas que se han aproximado a su obra. Así, L. Irigaray pienșa que, a pesar del interés merleau-pontiano por lo corporal, como todos los filósofos que le han precedido, sigue privilegiando lo visible, ${ }^{28}$ reduciendo lo táctil a éste y recubriendo, en suma, de idealismo la materialidad. Desde su perspectiva, hasta cuando Merleau-Ponty se refiere al tocar, especialmente cuando adopta la reversibilidad husserliana de las dos manos entrelazadas, el tacto está repleto de matices solipsistas que excluyen al otro e ignoran la diferencia sexual, de manera que se limita a describir lo visible, ahora duplicado. ${ }^{29}$ Por ello, según Irigaray, el filósofo sería otro continuador de la tradición occidental que asocia la razón con la visión; incurriría en la "metafísica de la luz", que relega a la mujer a la invisibilidad en la reproducción del logos y perpetúa un cuerpo imaginario masculino. Todo esto, a pesar de que Irigaray le reconoce a Merleau-Ponty el mérito de haber interpretado la oscuridad de lo maternal como la posibilidad misma de la visión. ${ }^{30}$ Ahora bien, si, como declara Butler, 'para Irigaray, lo 'femenino', que no puede decirse que sea algo, que participe de la ontología, consiste en -y aquí nos falta la gramática- situar por debajo de lo que se ha borrado esa necesidad imposible que posibilita toda ontología", ${ }^{31}$ el concepto de Chair de la endo-ontología no dualista merleau-pontiana y su negatividad constitutiva, correctamente interpretados, serían aptos para dar voz a las que han sido reducidas al silencio, a las que son silencio, un silencio que también habla y del que procede el habla.

Irigaray no ha explorado suficientemente estas posibilidades $y$, además, ha comprendido de un modo sesgado la obra de Merleau-Ponty. Desde

27. Del interés por las mismas provienen mis ponencias: "Mundo de la vida y pasividad del sueño", $M$ undo-da-vida-Racionalidade-Ciencia. A fenomenologia Luso-Brasileira, 5-9 de Diciembre 2007, Universidad de Lisboa; "Tiempo y Memoria en M. Merleau-Ponty", Congreso Internacional "Merleau-Ponty vivo", Universidad de Morelia (México), 4.09.08; "Merleau-Ponty: conciencia onírica, conciencia perceptiva", Coloquio Internacional Merleau-Ponty, Universidad de Zaragoza, 23 de Octubre 2008 (todas ellas en vías de publicación).

${ }^{28}$ Cf. Irigaray, L., Éthique de la différence sexuelle. Paris: Minuit, 1984, p. 164.

${ }^{29}$ Cf. Irigaray, L., op. cit., p. 148.

30 Cf. Irigaray, L., op. cit., pp. 144-145.

31 Butler, J., Bodies that Matter: on the discursive Limits of 'Sex'. New York: Routledge, 1993, p. 39 . 
nuestra perspectiva, éste no ofrece una metafísica de la luz, porque su nueva ontología se quedó inacabada y nos compete continuarla para sacar de la oscuridad nuevos problemas. No olvidemos que este fenomenólogo nos ha legado un concepto central para la misma que es la carne o visibilidad, que reúne al cuerpo estesiológico y al mundo, superando así los residuos dualistas que todavía pudieran quedar en el paradigma perceptivo de sus primeras obras. La fenomenología merleau-pontiana describe la génesis de esa visibilidad, el quiasmo entre lo visible y lo invisible, la reversibilidad carnal entre el ojo y el espíritu, en contraposición a la horizontalidad visual del sujeto ante a la realidad. No encontramos, por consiguiente, en su obra esa prioridad de lo visible a la que se refiere Irigaray. Por otra parte, lo visible es, para el filósofo, pre-objetivo, pero también pre-subjetivo $\mathrm{y}$, por tanto, puede aplicarse tanto al sujeto como al objeto; ambos se forman en el medium de la carne. Ella es visibilidad, entendida como la presentabilidad original y diferenciadora del vidente y de lo visible.

Así pues, cuando Merleau-Ponty analiza la visión, no es para absolutizarla, sino para internarse en su significación vital en contacto con el mundo visible e invisible. Es preciso añadir que el papel de la visión no es exclusivamente activo, no consiste únicamente en hacer visible; como acabamos de ver sólo es un componente de la visibilidad; llega a las dimensiones visibles de las cosas, que ya están ahí, pero también es puesta en cuestión e interrogada por ellas. Finalmente, la visión no es, para Merleau-Ponty, la culminación del sentir y, por tanto, no posee esa prioridad que Irigaray afirma. El sentir carnal merleau-pontiano es la reversibilidad del sentirse sintiendo y, por lo tanto, es mucho más que el acto de ver; obedece a la unidad sinestésica de los sentidos realizada desde cada esquematicidad corporal y a la conciencia de los mismos. El sentir opera por analogía con la concepción afectiva del conocimiento en la que intervienen todas las facultades.

Otro argumento que rebate la acusación de oculocentrismo dirigida a Merleau-Ponty es que éste ha superado el énfasis que Sartre puso en la mirada como relación primaria y negadora de la otra subjetividad. Aunque hemos desarrollado esto con mayor detenimiento en otro trabajo, ${ }^{32}$ digamos sucintamente ahora que, para Merleau-Ponty, el otro no se reduce a su mirada y menos aún a la mirada nihilizadora en la que piensa Sartre. A diferencia de éste, Merleau-Ponty sabe que la mirada que le dirigimos al otro no es un acto objetivante de la conciencia, sino una apertura a la visibilidad en la que ambos participamos. Desde esta nueva aproximación, el otro no me anula cuando me mira, sino que aporta a la visibilidad, desde la que ambos nos destacamos, una parte de lo visible que yo no veía.

32 Véase, López Sáenz, M.C., "Apuntes antropológicos basados en una relación: M. MerleauPonty y J.-P. Sartre", en Selles, J.F. (ed.) Modelos antropológicos del siglo XX. Navarra: EUNSA, pp. 83-114, especialmente pp. 97-99. 
Si bien, uno de los ejemplos empleados por Merleau-Ponty hace referencia a la mirada presuntamente masculina que objetiva a la mujer mientras ésta se siente mirada por sentir su cuerpo para otro, ${ }^{33}$ esta breve ilustración no sólo no comparte las características de la mirada sartreana a la que acabamos de referirnos, sino que tampoco ratifica el estereotipo de la mujer-objeto. En primer lugar, es preciso contextualizar el ejemplo en una nota de trabajo titulada "Telepatía-ser para otro-corporeidad". Dicha anotación comienza constatando que percibimos cada parte de nuestro cuerpo como visible para otro; paralelamente, la presencia de otro es posible porque cada fragmento corporal está envuelto por un halo de visibilidad. ${ }^{34}$ La visibilidad de mi cuerpo causa telepatía, es decir, hace que cualquier indicación de la conducta ajena active su posibilidad de hacerse visible. Con el ejemplo propuesto, Merleau-Ponty muestra que una mujer siente que su cuerpo es deseado sin mirar siquiera a los que la miran, porque sentir el cuerpo propio es también sentir su aspecto para otro. Lo que quiere poner de manifiesto no es tanto la cosificación del cuerpo femenino ante la mirada masculina, como el hecho de que cada perspectiva sobre el cuerpo ajeno es un punto de vista reversible. Esto puede apreciarse en el deseo erótico que aparece en la experiencia de ser visto, cuando la mirada de los otros se implica en la situación de su cuerpo en el mundo. Por tanto, a pesar de que Merleau-Ponty parece hacer gala con este ejemplo del tópico del cuerpo femenino como objeto de deseo, incluso del de la intuición femenina, en realidad sólo está ejemplificando la intercorporeidad de la intersubjetividad. ${ }^{35}$ Lo que realmente interesa es que la sensoriedad del otro está ya implicada de alguna manera en la mía, que ver no es ser vista, sino también ver a otros y a otras, verse desde el punto de vista de otros mundos y culturas. No es cierto, por consiguiente, que Merleau-Ponty tome la experiencia de los hombres como las únicas experiencias humanas. ${ }^{36}$

Insistiendo en sus críticas a Merleau-Ponty, Irigaray se detiene en la pieza clave de la nueva ontología merleau-pontiana, en la carne y en su reversibilidad. La filósofa considera que esta última anula las diferencias y, en concreto, la diferencia sexual. En nuestra opinión, Irigaray no ha sabido aprovechar las potencialidades de la reversibilidad de la carne. Se apresura a apostillar que las diferencias sexuales no son reversibles, pero Merleau-Ponty no afirma que lo sean. La carne es, para él, una categoría ontológica, no una adjetivación. Su reversibilidad no implica que una diferencia pueda sustituirse por otra y

33 "Por ejemplo, una mujer siente su cuerpo deseado y mirado por signos imperceptibles y sin necesidad de mirar a quienes la miran." (Merleau-Ponty, M., Le Visible et l'Invisible p. 299. La traducción es mía).

34 Cf. Merleau-Ponty, M., op. cit., p. 298.

35 Véase mi trabajo, "Intersubjetividad como intercorporeidad", La lámpara de Diógenes 5 (2004), pp. 57-71.

36 Merleau-Ponty en ningún momento declara esto que E. Grosz le atribuye en Volatile Bodies. Toward a corporeal Feminism. Bloomington: Indiana University Press, 1994. 
menos aún que se pueda eliminar. ${ }^{37}$ Bien entendida, la reversibilidad carnal conduce a la premisa ética de la necesidad de salir de sí para verse desde fuera y no absolutizar lo propio, para ponerse en el lugar del otro relativizando la propia posición. Por consistir en eso, la reversibilidad siempre es inminente, ${ }^{38}$ es decir, una virtualidad que nunca se realiza por completo.

Ciertamente, la carne remite a una anonimidad originaria, pero también a una progresiva diferenciación de la misma por écart. Podemos entender este término como desviación o divergencia sin matices peyorativos, como quiasmo entre identidad y diferencia, en definitiva, como lo diacrítico producido por la diferenciación significativa. El pensamiento francés, incluida Irigaray, lo ha heredado de Merleau-Ponty. No parece tenerlo presente cuando le acusa de concebir el cuerpo vivido como cuerpo masculino y de no marcar positivamente el cuerpo femenino. Olvida que el concepto merleau-pontiano de "carne" va más allá del cuerpo propio, sea éste masculino o femenino, que se extiende al mundo y a la naturaleza que, por cierto, es relegada por Irigaray cuando no la esencializa en la mujer o la concibe antropomorfizada. Ciertamente, Merleau-Ponty no analiza el cuerpo en términos de género, pero el hecho de que haya otorgado estatuto filosófico al cuerpo vivido y lo haya distinguido del cuerpo-objeto permite estudios de experiencias vividas ${ }^{39}$ desde el primero de diversos géneros y desde perspectivas y situaciones diversas.

Merleau-Ponty no trata apenạs la cuestión de la diferencia sexual, porque no es la única diferencia y porque sus investigaciones tienen como objeto la búsqueda del origen de las identidades y de las diferencias, tomadas conjuntamente, porque la diferencia siempre es relativa a aquello de lo que se difiere. Su fenomenología no nos ayuda demasiado a aislar los gestos y acciones que vienen determinados por el género, pero sí a tomar conciencia de la indeterminación en la existencia corporal. Por su parte, Irigaray, al centrar su atención en las diferencias, no sólo ha relegado la lucha por la igualdad y por el esclarecimiento de la identidad femenina, sino que ha incurrido en la personalización de las diferencias en la mujer.

Uniéndose a esta disquisición, J. Allen ha declarado que, cuando MerleauPonty sentencia que no tenemos un cuerpo, sino que somos nuestro cuerpo, la. referencia de éste es el cuerpo masculino, no el femenino. ${ }^{40}$ De nuevo, hemos de

37 Véase un desarrollo de esta problemática, en López Sáenz, M.C., "Hermenéutica fenomenológica de la existencia intercultural", La Lámpara de Diógenes 12-13 (2006), pp. 126-152.

38 Cf. Merleau-Ponty, M., Le Visible et l'Invisible, p. 194.

39 Una relación de dichos estudios en España en mi contribución, "Phänomenologie und Feminismus in Spanien", Die Philosophin, 26 Dezember 2002, pp. 57-69. Véase también mi trabajo, "Interpretación feminista de la corporalidad: Merleau-Ponty revisitado", Estudios filosóficos 152 (2004), pp. 45-58.

${ }^{40}$ Cf. Allen, J., "Through the Wild Region: An Essay in Phenomenological Feminism", Review of Existential Psychology and Psychiatry 18 (1, 2 y 3) (1982-3), p. 245. 
insistir en que el filósofo no ha escrito esto explícitamente jamás y la sospecha interpretativa no ha de preceder a la comprensión de lo que los textos dicen.

Lo cierto es que la fenomenología merleau-pontiana nos permite a las mujeres reflexionar sobre nuestras experiencias vividas, a favor o en contra de las imágenes corporales a las que nos someten. Es verdad que casi todos los ejemplos que el filósofo pone en Fenomenología de la percepción sobre la sexualidad son masculinos y heterosexuales, a excepción del caso de la muchacha a la que se le ha prohibido ver a su amante y reacciona perdiendo la voz y el apetito. Con ella muestra el autor que determinadas disfunciones no son voluntarias, ni fisiológicas, puesto que la mujer recobra el habla cuando la prohibición desaparece. La realidad es que hasta las prohibiciones se encarnan como rupturas traumáticas de la coexistencia y que las mujeres introyectan en sus cuerpos el silencio; éste se traduce en la pérdida de la memoria de la identidad corporal ${ }^{41} \mathrm{y}$ de cierta libertad de comportamiento. Con posterioridad a la Fenomenología de la Percepción, en Lo visible y lo Invisible, concretamente, en el capítulo "El Entrelazamiento-El quiasmo", Merleau-Ponty supera cualquier residuo dualista. En las notas de trabajo con las que finaliza esta obra abundan las imágenes femeninas. ${ }^{42}$

Sin embargo, Merleau-Ponty sólo aspiraba a marcar positivamente el cuerpo vivido como tal, a comprender la esquematicidad corporal como base de la intercorporeidad y estructura general compartida por cada particularidad, por la cual la génesis de cada cuerpo es co-generación de otros en el seno de la carne. Esta relación intrínseca entre los cuerpos reclama un desarrollo de mi relación con los demás que me aproxima a la ética. De ahí que la fenomenología merleau-pontiana del cuerpo ofrezca interesantes recursos para comprender la dimensión corporal del cuidado y también para investigar los aspectos corporales de la moralidad.

El hecho de que Merleau-Ponty dedique a la sexualidad el capítulo de su Fenomenología de la percepción, "El cuerpo como ser sexuado", revela, por otra parte, su rechazo del dualismo alma-cuerpo que olvida la diferencia sexual $\mathrm{y}$, en general, toda diferencia, al presuponer que el sujeto es neutro y universal. Para Merleau-Ponty, el cuerpo es sexuado, pero no es eso exclusivamente. Por un lado, en su obra, el cuerpo pierde su carácter físico dado y pasa a ser considerado como campo de posibles acciones; por otro, la sexualidad no sólo se enraíza en lo biológico, sino también en las motivaciones, en las actitudes y en las relaciones.

En este capítulo, Merleau-Ponty se adhiere a las concepciones de M. Mead sobre la masculinidad y la feminidad. Con posterioridad, volverá a insistir en el

${ }^{41}$ Cf. Merleau-Ponty, M., Phénoménologie de la Perception, pp. 188-189.

${ }^{42}$ Un trabajo que aprovecha dichos ejemplos es el de Holland, N.J. "In a diferente ch(i)asm. A Feminist Rereading of Merleau-Ponty on Sexuality", en Hass, L./Olkowski, D. (eds.), Rereading Merleau-Ponty. New York: Humanity Books, 2000, p. 325. 
valor de su generalización del psicoanálisis, que, aun reconociendo con Freud que masculinidad y feminidad dependen de las relaciones interpersonales, rechaza la convicción éste de que toda sexualidad sea masculina, que la situación edipiana sea el eje central de la civilización, y la sexualidad femenina se reduzca a una simple variante. "Para M. Mead: la situación edipiana descrita por Freud no es más que una solución particular de un problema que parece universal", ${ }^{43}$ pero que no lo es; el auténtico problema al que se enfrentan todas las culturas es el de las relaciones entre padres e hijos, entre sociedad y naturaleza y entre el yo y el otro. Merleau-Ponty acepta la diversidad de tipos de relaciones del niño con la madre definida por Mead y las diferentes pósibilidades culturales de la relación masculinidad-feminidad que se siguen de ellas. Aquéllas son causa de éstas, pero también efectos, porque los niños se convierten en adultos ỳ tienden a reproducir la misma estructura de la relación entre masculinidad y feminidad. "Ninguna de las categorías se encuentra realizada en estado puro. Pero sentimos que la relación masculinidad-feminidad es solidaria de toda una técnica de relaciones de la madre con el hijo y de las relaciones del hombre con la naturaleza". ${ }^{44}$

Así es como el filósofo se opone al dualismo masculinidad-feminidad conviniendo con la antropóloga en que los caracteres femeninos y masculinos difieren según las configuraciones de cada cultura y según las relaciones entabladas con la naturaleza. Además, las conformaciones culturales no se adquieren de una vez para siempre, sino que pueden cambiar, porque son Stiftungen o "institucionalizaciones" que permiten la intervención del sujeto en los sentidos que se han ido sedimentando. Esta capacidad de reactivación individual de lo que se ha mantenido entra en contradicción con el pansexualismo, porque la sexualidad no es, para Merleau-Ponty, ni el centro de la existencia, ni un estrato de ella que pueda obviarse, sino otra dimensión de la existencia en devenir.

En el curso que Merleau-Ponty impartió en el Collège de France en 1954-1955 sobre la institución, define a ésta por la dialéctica entre universalismo y particularismo y como una relación entre la persona, la historia pública y la institución anónima, "pero la persona misma (debe ser) comprendida como institución, no como conciencia de...". ${ }^{45}$ Esta interrelación entre lo personal y lo público que define a la institución, pone de manifiesto que, para nuestro filósofo, no hay causalidad entre los términos, ni determinismos absoluto del individuo, sino ecos particulares de los sistemas simbólicos compartidos. Como ejemplo de ello, en las notas de este curso encontramos una anotación que hace referencia a S. de Beauvoir y que entiende a la mujer como institución social y no

${ }^{43}$ Merleau-Ponty, M., Merleau-Ponty à la Sorbonne. Résumé de Cours 1949-1952. Grenoble: Cynara, 1989, p. 489.

${ }^{44}$ Ibid., p. 492.

${ }^{45}$ Merleau-Ponty, M., L'institution. La Passivité. Notes de cours au Collège de France 19541955. Paris, Belin, 2003, p. 47. 
sólo biológica, aunque entre lo social-objetivo y la institución biológica habría, según Merleau-Ponty, conciencia de una situación ${ }^{46}$ que no nos determina desde fuera, sino que nos acompaña constantemente. De nuevo Merleau-Ponty recurre a Beauvoir y a su concepción de la mujer como momento en la dinámica de la sociedad masculina. Descubre en ella el prejuicio sartreano de concebirla como conciencia o sujeto puro en una situación que no es la suya, cuando, en realidad, "la mujer no puede luchar contra la opresión sin reivindicarse a sí misma en su diferencia". ${ }^{4}$

De ello podemos deducir que la fenomenología merleau-pontiana del cuerpo vivido permite comprender la diferencia sexual sin objetivarla. Por otra parte, Merleau-Ponty interpreta a Freud sin renunciar a la intencionalidad. Concibe la sexualidad como una relación intencional entre un sujeto corporal y una situación concreta, como una forma de intersubjetividad, un medium para realiżar los proyectos existenciales. Sus diferentes expresiones son posibilidades inherentes a la existencia corporal y ninguna tiene prioridad sobre.las otras.

Desde la corporalidad, entendida como poder universal de incorporación, siguiendo a M. Klein, Merleau-Ponty interpreta el freudismo corrigiendo su determinismo sexual, entendiendo que la libido freudiana no es una entelequia en la que hubieran cristalizado todas las fases del desarrollo, sino que depende de la experiencia del sujeto que, para Merleau-Ponty es prioritaria. Por su parte, el sexo no es una causa única y total, sino una dimensión ineluctable, fuera de la cual nada humano puede permanecer, "porque no hay nada humano completamente incorporal". ${ }^{48} \mathrm{La}$ sexualidad es tan fundamental para la existencia porque es una de las manifestaciones del cuerpo vivido, una prolongación de su intencionalidad operante (Fungierende) que, a su vez, revierte sobre dicha intencionalidad y permite pensarla como deseo de aquello hacia lo que tiende. La experiencia del deseo nos hace tomar conciencia de nosotras mismas como subjetividades autónomas y, a la vez, como seres dependientes. ${ }^{49}$

El enfermo Schneider, estudiado por K. Goldstein, no es capaz de esa experiencia, según Merleau-Ponty. ${ }^{50}$ No tiene ningún defecto orgánico, sino un déficit que afecta a su cuerpo vivido, una desintegración de la globalidad que es la existencia. Una de las estructuras de ésta es la erótica. Scheneider carece de esa integración funcional y vital que es la esquematicidad corporal y en la que la sexualidad no es ni una simple función, ni un instinto, sino una intencionalidad motora,

46 Ibid.

47 Ibid., p. 48.

48 Merleau-Ponty, M., Résumés de Cours 1952-1960, p. 178.

49 Cf. Merleau-Ponty, M., Phénoménologie de la perception, p. 195.

${ }^{50}$ Ibid., p. 182. 
el poder general del sujeto psicofísico de adherirse a medios diferentes, de atenerse a diferentes experiencias, de adquirir estructuras de conducta. ${ }^{51}$

La sexualidad está conectada con la vida total del sujeto, pero no como un mero epifenómeno de ella. Es una de las expresiones existenciales de la intencionalidad hacia el otro, pero no es algo privado, sino una dimensión de la co-existencia intercorporal, una atmósfera ${ }^{52}$ presente en nuestra vida que proporciona un carácter erótico a todo lo que somos y hacemos. Pone de manifiesto la anonimidad que anida en la sensibilidad experimentada universalmente en la encarnación, en la indistinción entre conciencia y corporalidad. Pero la sexualidad no se limita a ser una modalidad de la intencionalidad, sino que, a su vez, es modalizada y recreada por nuestra vida intencional, hasta el punto de que "si la existencia se difunde en la sexualidad, recíprocamente ésta se difunde en la existencia". ${ }^{53}$ En suma,

hay ósmosis entre sexualidad y existencia, es decir, que si la existencia irradia sobre la sexualidad, recíprocamente, la sexualidad lo hace en la existencia, de manera que es imposible asignar por una decisión o acción dada, la parte de motivación sexual y la de las otras motivaciones, es imposible caracterizar una decisión o acto como 'sexual' o 'no sexual'. 54

Esta imposibilidad obedece a la indeterminación esencial de nuestra existencia, a su apertura constitutiva.

El cientificismo desconoce esta condición existencial de la sexualidad, como ignora las constantes de la conducta y las actitudes generales, más allá del comportamiento propiamente sexual, que reflejan las diferencias entre hombre y mujer. En cambio, el sentido común las tiene en çuenta. Merleau-Ponty considera que es poco probable que se constituyan en la experiencia de cada uno por aproximaciones inductivas; más bien, cree que se originan de golpe y

se revelan en una expresión facial, en un gesto. El descubrimiento de correlaciones causales - por ejemplo, las influencias endocrinas que determinan el conjunto de las características sexuales- no sólo tiene como efecto "completar" la noción común; también puede conducirnos a modificar nuestra idea del ser macho y hembra para integrar en ella ciertas actitudes parciales que se le escapan al conocimiento común. ${ }^{55}$

Hasta la comprensión de lo biológico requiere la superación del mecanicismo y del determinismo para sacar a la luz la relación de los hechos con sus significaciones, descubriendo una actitud general hacia las cosas. No tiene sentido, 
por tanto, ni reducir la sexualidad a la genitalidad ni relegarla al ámbito de la conciencia pura, puesto que se manifiesta en todo el sujeto corporal (en sus gestos, sus movimientos, su voz, sus aspectos visuales, motores, táctiles, etc.) y la ciencia pueden ayudar a las elaboraciones generales del significado sexual, porque éste surge del diálogo entre mi existencia corporal y las otras subjetividades encarnadas; de ahí que no pueda entenderse de manera puramente mecánica.

El diálogo en la coexistencia comienza ya en la percepción del otro y de la otra como cuerpos vividos desde el mío, que caracteriza a la percepción erótica; no consiste en una simple cogitatio hacia un cogitatum, sino en una percepción erótica, puesto que parte del cuerpo, apunta a otro cuerpo y tiene lugar en el mundo, no en la conciencia. Si añadimos que el cuerpo vivido no es el mero cuerpo biológico, sino el que siente, es capaz de empatizar (Einfühlen) y desea, podemos concluir, sin incurrir en determinismos, que "la estructura estesiológica del cuerpo humano es una estructura libidinal, la percepción un modo de deseo, una relación de ser y no de conocer". ${ }^{56}$

Merleau-Ponty identifica el cuerpo libidinal con el deseo, entendido éste como intencionalidad operante, como apertura direccional de la carne del cuerpo a la del mundo. Las estructuras vitales que habitamos están investidas de esa libido que permite la experiencia del afuera, el encuentro con un extraño que deviene, al unísono, familiar. Como dice R. Barbaras, Merleau-Ponty no concibe la diferencia sexual como una determinación intrínseca; tampoco como una donación del otro cuerpo como sexualmente diferente, sino como la inscripción de ambos en un mundo, como un proceso que tiene lugar en el seno de una relación; por ello, en su opinión, no habría mujeres y hombres, sino un solo eje del Deseo en cuyo seno estos dos polos se constituyen. ${ }^{57}$ El Deseo sería el campo de la existencia desde el que se destacan otras dimensiones.

Es cierto que Merleau-Ponty no problematiza ni las diferencias ni las analogías entre la sexualidad femenina y la masculina, pero comprende filosóficamente que la sexualidad forma parte, tanto de las esferas pasivas como de las activas de nuestra vida de individuos en sociedad. De ningún modo niega las diferencias sexuales, sino que, en todo caso, pone entre paréntesis la determinación dualista por las que se rige el establecimiento de las mismas. De esta manera, deja abierta la posibilidad de pensar las diferencias sin oponerlas y $\sin$ abocar a la indiferencia ante las mismas. Esto es así porque Merleau-Ponty no sólo entiende, como acabamos de ver, las diferencias genéricas contextualizadas en las relaciones interhumanas, sino que, también a la inversa, concibe

${ }^{56}$ Merleau-Ponty, M., La Nature, p. 272.

${ }^{57}$ Cf. Barbaras, R., De l'être du phénomène. Sur l'ontologie de Merleau-Ponty. Grenoble: J. Millon, 1991, p. 311. En una de sus últimas obras, el autor se ocupa del deseo, no como una categoría psicológica, ni como una afecto, sino como clave de la vida para una nueva ontología fenomenológica (véase Barbaras, R., Introduction à une Phénoménologie de la vie. Paris: Vrin, 2008, pp. 255-367). 
las relaciones intersubjetivas por analogía con las intersexuales, es decir, como papeles complementarios que no existen cada uno por separado: masculinidad implica feminidad y a la inversa.

Esta reversibilidad relacional es la que le separa de las explicaciones deterministas y le lleva a considerar, por ejemplo, que el pensamiento de Lévi-Strauss, que basa las relaciones sociales en el intercambio de las mujeres, es una construcción artificial desde el punto de vista de un hipotético kosmotheoros. Merleau-Ponty critica esta postura en una nota de sus cursos por considerarla, además, androcéntrica, por absolutizar injustificadamente una situación concreta, ya que el

postulado de interpretación por intercambio (implica) masculinismo. Lo que el psicoanálisis tendría que decir (contra Freud) de este masculinismo. Quizás es adecuado para las sociedades existentes, no para sociedades posibles. 'Mujeres', 'hombres' (implica) a priori del esquema de Lévi-Strauss, -que el psicoanálisis contesta (postulado de naturaleza). ${ }^{58}$

En esta nota Merleau-Ponty sospecha que la noción de intercambio no es una verdadera interacción, ya que presupone que las mujeres sólo son intermediarias entre hombre y hombre, mercancías en su mercado, no verdaderos sujetos coexistentes con ellos. Dicho intercambio cuyo centro es "masculinista" 59 no es generalizable a todas las sociedades. Para pensar lo social, se necesita una noción más universal de intercambio entre sujetos: la coexistencia en la que se funda la intercomprensión. Esta última va más allá de las relaciones sujeto-objeto o dominante-dominado.

Asegurar que la sociedad se basa en el intercambio de mujeres es generalizar imprudentemente las relaciones sexuales y tomar como paradigma de las mismas el de la dialéctica del amo y del esclavo. En contra de la misma, Merleau-Ponty aborda la sexualidad como una dialéctica concreta e inacabada, como tensión de una existencia hacia otra que la niega y sin la cual no se sostiene, una dialéctica que sólo arroja síntesis de transición, porque cada uno de los elementos no es anulado por el otro, siendo lo fundamental el polimorfismo, la transitividad, ${ }^{60}$ la matriz de la que nace el universo vertical o carnal.

De la misma manera que la sociedad no se reduce al comercio de las mujeres realizado por los hombres, la masculinidad no es la que constituye ante sí la feminidad, sino que ambas se van formando en la praxis de hombres y mujeres situados e interrelacionados, de la misma manera que cada sujeto se constituye desapropiándose de sí y apropiándose de lo otro hasta producir una

58 Merleau-Ponty, M., L'institution. La Passivité. Notes de cours au Collège de France 1954-1955, p. 117 (nota al pie). Fue David Scorso, investigador de las relaciones entre Merleau-Ponty y Lévi-Strauss, quien me hizo reparar en esta breve nota.

59 Merleau-Ponty, M., L'institution. La Passivité. Notes de cours au Collège de France 1954-5, p. 121 (nota al pie).

${ }^{60}$ Cf. Merleau-Ponty, M., Le Visible et l'Invisible, p. 274. 
intersección en la que lo masculino implica lo femenino y a la inversa. De aquí se sigue que las identidades sexuales no son constantes en la multitud de comportamientos, sino que se desarrollan y cambian con el tiempo.

Masculinidad y feminidad son variaciones de nuestra manera básica corporal de relacionarnos con el mundo, estilos que expresan un sentido de la vida encarnada, potencias expresivas del cuerpo vivido, formas de habitar el mundo y darle significado desde el presente y la singularidad reactivando todo el sentido adquirido. Con el concepto de "estilo", Merleau-Ponty sigue a Husserl al entender las diferencias y las identidades, incluidas las sexuales, no como determinaciones biológicas; tampoco como construcciones culturales, sino como expresividades del cuerpo vivido en su relación con el mundo. Vivenciada así, nuestra existencia queda marcada por estilos femeninos y masculinos. Ambos son una mezcla de actividad y pasividad. No se puede aventurar quie el masculino sea un estilo eminentemente activo, mientras que el femenino sea pasividad, ni tampoco comprender la actividad como espontaneidad pura y como contraria a la receptividad y a la afectividad, porque todo estilo implica algo que se hereda estilizándolo.

La diferencia sexual forma parte de cada estilo, pero no consiste en una diferencia radical; én esto, Merleau-Ponty y Beauvoir estarían de acuerdo y discreparían con respecto a Lévinas; no compartirían su concepción de lo femenino como lo Otro absoluto, tan distanciado de la reciprocidad de la que goza la intersubjetividad fenomenológica. Esto no significa que conciban la identidad sexual como una cuestión de elección voluntaria. Dicha identidad se forma y experimenta en nuestros posicionamientos, en nuestros hábitos inscritos en el cuerpo, pero susceptibles de reescrituras, porque vivimos nuestro cuerpo como una constante que posibilita una infinita variabilidad de respuestas a sus diferentes situaciones. El ser humano no está dado, sino que se hace, es una idea histórica y no una especie natural, pero se forma sobre unas bases naturales aunque siempre transcendiéndolas. Por lo que respecta a la mujer, las determinaciones sociales han convertido sus diferencias en discriminaciones quedando subordinadas a las diferencias que marcan positivamente al hombre.

Merleau-Ponty comprende, sin embargo, ya en 1954 que la lucha de la mujer por la igualdad no tiene como objeto la identificación con el hombre, sino la eliminación de la jerarquía establecida que la sitúa en la frontera de la humanidad; por tanto,

no se trata de abolir las diferencias, sino de ver que no van al corazón o a la inteligencia y que, deducción hechạ de los talentos y vicios que deben a su condición marginal, las mujeres pueden ser seres humanos. ${ }^{61}$ 
Aunque son diferentes y no viven la misma vida, mujeres y hombres han de dejar de verse como grupos opuestos y afianzar sus relaciones, desapropiándose al mismo tiempo que acometen una auto-apropiación reflexiva. Muy cerca del feminismo marxista, Merleau-Ponty propone, en este artículo, que las mujeres se unan entre sí y con los hombres que viven también oprimidos, sin verse abocadas a imitarlos y a negar sus rasgos más propios. Como hemos visto, éstos se manifiestan en estilos de ser en el mundo y de relacionarse con los otros. Es lógico, por tanto, que Merleau-Ponty sospeche de los estereotipos sexuales de masculinidad y feminidad y los considere prejuicios que dificultan la investigación de las verdaderas diferencias entre hombres y mujeres.

En su cátedra de psicología en la Sorbona puso en entredicho, por ejemplo, la fragilidad atribuida a la naturaleza femenina. La consideraba una mera representación cultural. Es una falacia creer que haya una naturaleza femenina y otra masculina. ${ }^{62}$ Un investigador debe desprenderse de ella y reintegrar a los seres humanos en sus relaciones sociales, históricas y educativas. Así pues, lo que determina las diferencias de la mujer con respecto al hombre no es esa supuesta "naturaleza", sino la socialización recibida. Ésta no sólo afecta a los cambios físicos del individuo, sino a la comprensión de los comportamientos a través de los cuales se experimentan. Esto significa que lo que determina la conducta individual es la interrelación entre el nivel fisiológico, el psíquico y el social. Así, por ejemplo, Merleau-Ponty se niega a identificar el advenimiento de la menstruación con la pubertad. ${ }^{63}$ Desde su perspectiva, la primera sólo se convierte en un elemento de la segunda cuando es aceptada por la joven cuyas conductas, a su vez, han madurado en el contexto social.

La menstruación no es un mecanismo automático que introduzca a la niña en la pubertad; primero, ha de ser integrada por ella; tampoco basta con acumular conocimientos sobre su proceso. El desarrollo de la adolescente no se cifra en una serie de fenómenos cognitivos o intelectuales superpuestos a los fenómenos de orden corporal; sólo se cumple cuando las transformaciones corporales y las funciones nuevas han sido integradas en el conjunto de la vida del sujeto:

Existe, pues, una relación singular entre el cuerpo y el sujeto total. El cuerpo debe ser considerado como un espejo, como expresión del psiquismo de todo sujeto, como expresión de la historia psicológica. El desarrollo anónimo del cuerpo no es nada mientras no esté integrado en su historia psicológica. ${ }^{64}$

El desarrollo corporal no se explica por el psíquico ni tampoco al revés, porque no tiene ni una causa mecánico-corporal ni un fin determinado por la

62 Cf. Merleau-Ponty, M.: Merleau-Ponty à la Sorbonne. Résumé de Cours 1949-1952, p. 470.

63 Ibid., p. 504.

64 Ibid., p. 505. 
conciencia. El individuo realiza una reprise con las posibilidades que le brinda su campo corporal, recortándose desde él para establecer relaciones, ${ }^{65}$ darles significado y hacerlas suyas. Por eso el desarrollo no es ni un destino ni una libertad absoluta.

Guiado por esta misma teoría hermenéutica, Merleau-Ponty se refiere al embarazo analizando los sentimientos que causa en la mujer. Ésta se siente alienada de su propio cuerpo debido a los cambios corporales que experimenta y a que éstos tienen que irse progresivamente acomodando a otro modo de habitar el mundo que pronto compartirá con su bebé. La mujer vive su embarazo participando en un proceso anónimo y ambivalente, porque no es el mero resultado de una decisión suya,

su embarazo no es un acto como otros que se cumple con su cuerpo: es más bien un proceso anónimo que toma forma a través de ella y de la que ella es sólo la sede. $^{66}$

Por eso es por lo que la futura madre experimenta que su cuerpo ya no le pertenece $y$, a la vez, que el niño que lleva en sí es una prolongación de su cuerpo; le invade una sensación de vida ampliada, de reversibilidad de la carne, en tanto magma, claustro materno, sujeto-objeto previo a las diferenciaciones, materia interiormente trabajada en su propia ontogénesis:

Durante todo su embarazo, la mujer vive un gran misterio que no es ni del orden de la materia ni del orden del espíritu, sino más bien del orden de la vida ${ }^{67}$

como auto-engendramiento. El filósofo está haciendo suyos en estos textos $L a$ psicología de las mujeres de H. Deutsch. Desde la óptica merleau-pontiana, estas experiencias vividas en el embarazo reproducen la ambivalencia con la que experimentamos todas las relaciones humanas de la que se desprenden sentimientos negativos y positivos: la madre posee al niño y es poseída por él; por otra parte, Merleau-Ponty constata asimismo la ambigüedad de la actitud del padre en relación con sus hijos. ${ }^{68}$ De todo ello concluye que el denominado "instinto maternal" no sólo bastante débil, sino que, además, la identificación de cualquiera de los progenitores con su hijo o hija es construida, es decir, "es una realización humana creada por la vida común". ${ }^{69}$

De aquí se sigue el rechazo merleau-pontiano del complejo de Edipo del niño y del de castración de la niña, por no considerarlos determinantes de sus diferencias. Ya hemos visto que éstas no se construyen como deficiencias 
respecto a un ideal, sino como estilos. Desde ellos, es posible desarrollar una fenomenología de la existencia femenina encarnada que no sea puramente una negación de la masculina. En nuestra opinión, I.M. Young (fallecida en 2006) ha sido pionera en ello.

Como Merleau-Ponty, partía de la constatación de que era la situación particular de la mujer la que le privaba de subjetividad y transcendencia ${ }^{70}$ y se ponía de relieve en sus comportamientos corporales: la mujer se queda en la inmanencia incluso cuando se mueve; ${ }^{71}$ vive su cuerpo como si de una cosa se tratara manteniéndose a distancia de cualquier compromiso con las posibilidades que el mundo ofrece. Todo ello se debe a que su estilo de ser en el mundo se define por la timidez, la postura estática y la inseguridad ${ }^{72} \mathrm{de}$ la motricidad femenina. Debido a ello, la mujer proyecta un espacio limitado para su "yo puedo" que es vivido por ella como algo ya constituido. Inhibe, por tanto, su intencionalidad operante. ${ }^{73}$ La contrapartida temporal de esta situación apenas es analizada por Young. Sólo cuando, en continuidad con Merleau-Ponty, se detiene en el descentramiento del sujeto que se produce en la mujer embarazada, en su experiencia vivida del cuerpo como propio y ajeno, añade que esto se produce en una única temporalidad.

Según la filósofa, la experiencia de la mujer embarazada es el paradigma de la realidad corporal subjetiva-objetiva, idéntica y diferente, al mismo tiempo, porque determina la vivencia de la dehiscencia del cuerpo, ${ }^{74}$ la experiencia de otra vida y de la preparación para ella. Las resonancias de la Chair merleau-pontiana y de sus propiedades son evidentes. En nuestra opinión, Young ha desarrollado uno de los impensados de Merleau-Ponty en el marco de la fenomenología corporal de éste. En ella ha encontrado un buen correctivo para ese nuevo dualismo entre el sexo y el género que ha hecho abstracción del cuerpo vivido. Desde el horizonte merleau-pontiano, la autora pretende teorizar la subjetividad sexual evitando caer tanto en el reduccionismo biológico como en el esencialismo del género. ${ }^{75}$

${ }^{70}$ Cf. Young, I.M., "Throwing like a Girl. A Phenomenology of Feminine Body comportment, Motility and Spatiality", en Allen, J./Young, I.M., The Thinking Muse. Bloomington: Indiana University Press, 1989. p. 55.

71 Ibid., p. 59.

72 Ibid., p. 58.

${ }^{73}$ Mientras que la intencionalidad corporal es expresada por Merleau-ponty como un "yo puedo", como proyección virtual del cuerpo y cumplimiento mundano de sus objetivos, la intencionalidad corporal femenina está, según Young, inhibida, es decir, se dirige a un fin proyectado desde su "yo puedo" y simultáneamente, niega su obligación respecto a tal fin desde un "yo no soy capaz" auto-impuesto; por eso, generalmente su motricidad es inefectiva y no consigue cumplir sus objetivos (cf. Young, I.M., op. cit., p. 148).

${ }^{74}$ Cf. Young, I., Throwing Like a Girl and Other Essays in Feminist Philosophy and Social Theory. Bloomington: Indiana University Press, 1990, p. 161.

75 Cf. Young, I.M., "Lived Body vs Gender: Reflections on social structure and subjectivity", en Proudfoot, M. (ed.), The Philosophy of the Body. Oxford: Blackwell Publishing, 2003, 
Compartimos esta intención, porque pensamos que la fenomenología que hemos de continuar aplicando a los problemas que nos conciernen, no ha de perder de vista las desigualdades en razón del género así como la reeducación crítica de éste. Asimismo la fenomenología permite al feminismo pensar el cuerpo vivido, que no es sólo sexualidad vivida, sino el nudo ontológico del ser con el mundo. Su epistemología permite dialectizar los conceptos de sexo y género, entenderlos como otra de las manifestaciones de la unión entre naturaleza y cultura que somos, como el "estilo". Fenomenológicamente entendido, éste permite conciliar una cierta indeterminación con una constante continuidad entre diversos modos de vivir el género y el cuerpo. De este modo, se descarta que existan diferencias biológicas inmodificables que determinen variaciones supuestamente innatas y también que haya categorías trasculturales inflexibles.

La corporeidad nos pone en relación con el mundo y se expresa en nuestras conductas, pero al mismo tiempo ella es modulada por patrones culturales e identidades sociales. Por otro lado, el estilo corporal es esa forma singular de apropiación del mundo y, por tanto, es algo más que género. Estilizamos sometiendo la tradición a una deformación coherente, es decir, a una manera singular de habitar el mundo de los significados enriqueciéndolo con nuestros propios sentidos. El estilo conserva lo sedimentado en las apropiaciones individuales, de modo que hace desaparecer la dicotomía esencia-individuo borrando también toda jerarquía. $^{76}$

Young no ha reparado en estas posibilidades de la nueva ontología merleau-pontiana. A pesar de su apropiación selectiva de las ideas de este filósofo, afirma que la fenomenología existencial continúa con el humanismo de la filosofía moderna que trata al sujeto como neutro y universaliza la experiencia masculina. ${ }^{77}$

Es cierto que Merleau-Ponty no ha analizado las deformaciones coherentes de la realidad que realizan los hombres y las mujeres concretos, ni las formas sociales y culturales por las que construimos nuestros hábitos corporales, pero ha sabido mostrar que éstos no son cualidades secundarias, sino constituyentes del estilo: un juego de prácticas significativas inscritas en los cuerpos y en la jerarquía de géneros que nos es impuesta.

Aún reconociendo el interés de las aportaciones de Young, consideramos que el estilo por ella descrito no es el del cuerpo vivido o fenoménico del que habla Merleau-Ponty, sino el de un cuerpo objetivado que vive su corporalidad tal y como le es impuesta desde fuera y que, en el caso del cuerpo femenino, se está enfrentando a la amenaza constante de invasion de su espacio corporal y de

pp. 94-130, p. 94.

76 "No hay jerarquia de órdenes o capas o planos (siempre fundada en la distinción entre individuo-esencia." (Merleau-Ponty, M., Le Visible et l'Invisible, p. 324).

${ }^{77}$ Cf. Young, I.M., Throwing Like a Girl and Other Essays in Feminist Philosophy, pp. 14-15. 
su tiempo ${ }^{78}$ Sus descripciones de las particularidades de la orientación corporal femenina son interesantes ejercicios de psicología o sociología fenomenológica, pero no pueden generalizarse a todas las mujeres. En cambio, Merleau-Ponty no hace apenas análisis empíricos, sino fenomenológicos; aquéllos son necesarios pero no suficientes.

En lugar de subrayar las carencias de Merleau-Ponty, Young podría haber empleado su herencia para someter a crítica sus propias descripciones fenomenológicas; por ejemplo, para poner en cuestión su concepción negativa de la orientación corporal femenina. Nos da la impresión de que éșta se basa en una noción cuantitativa de la espacialidad y de la motricidad; toma como paradigma de esta última al atletismo, una actividad poco habitual que, además, delata que Young está considerando la experiencia corporal masculina como patrón de la existencia. En cambio, Merleau-Ponty tomaba como modelo la corporeidad habitual que estructura la existencia corporal sin encorsetarla para siempre, puesto que la adquirimos y modelamos mediante el aprendizaje, la aculturación e incluso la transformación de las prácticas. Demostraba así que el cuerpo como hacedor de hábitos es significado encarnado y sedimentado en la biografía de los individuos que siempre permanece abierta a su modificación.

También Butler emplea ocasionalmente conceptos y terminología merleau-pontiana con objeto de evitar el error de pensar el cuerpo como algo puramente natural o como medio pasivo de las inscripciones culturales. Interpreta correctamente que, para Merleau-Ponty, el cuerpo es un lugar de apropiación y un mecanismo de transformación. ${ }^{79}$ A pesar de ello, afirma que en su filosofía prevalece la sexualidad masculina, la cual se caracteriza por una mirada des-corporalizada que define su objeto como un simple cuerpo ${ }^{80}$ Hasta declara que, para Merleau-Ponty, el sujeto normal vidente es el hombre y el cuerpo visto es el de la mujer, ${ }^{81}$ que éste denota una esencia mientras que los cuerpos en general denotan existencia. De ahí deduce que la existencia no pertenece a la mujer y que los cuerpos son masculinos. ${ }^{82}$ Sin embargo, de la lectura de Merleau-Ponty no se sigue esto; para él, todo cuerpo propio es existencia, y ésta es la que hace manifiesta, encubre o recubre cualquier situación concreta. Finalmente, toda existencia se produce en coexistencia, toda subjetividad se gesta en la intersubjetividad y toda corporalidad en la intercorporalidad.

78 En el trabajo, "Tiempo y Memoria en M. Merleau-Ponty", al que ya aludimos en nota 27, nos hemos detenido en la memoria del cuerpo y en la concepción proustiana-merleau-pontiana de éste como guardián del pasado.

79 Cf. Butler, J., "Sexual Ideology and Phenomenological description. A feminist critique of Merleau-Ponty's phenomenology of Perception", en Allen, J./Young, I.M., The Thinking Muse, cit., p. 86.

80 Ibid.

${ }^{81}$ Ibid., p. 93.

${ }^{82}$ Ibid., p. 94. 
Las apreciaciones de Butler están determinadas por el análisis foucaultiano del cuerpo que le permite desvincular el género de cualquier determinación natural. Desde estas coordenadas, no es capaz de superar ni la alienación de nuestro ser humano de la naturaleza ni el punto de vista androcéntrico que reduce todo a su uso cultural "humano". Además, Butler incurre en una nueva dicotomía: la del cuerpo-género. Al desnaturalizar el cuerpo, lo desencarna; el género, por su parte, se acaba reduciendo a un mero artificio. Algo parecido ocurre con el sexo, concebido por Butler como una construcción social similar al género. ${ }^{83} \mathrm{Al}$ razonar así, la filósofa se priva de fuentes para distinguir entre normas de identidad que deben ser subvertidas y normas que pueden ser reivindicadas, ya que todas son creadas socioculturalmente y exigen que realicemos nuestra identidad de una u otra manera. Ahora bien, ¿Dónde encontraremos los patrones para configurar identidades más positivas?

La identidad no es sólo una construcción social y cultural introyectada por el individuo, sino también una realización individual desde una situación material determinada y el resultado de una interpretación. Concebir el sexo y también el género como realizaciones exclusivamente culturales reproduce la idea hermenéutica de que el sentido reside en el intérprete; sin embargo, la identidad cultural en general y la identidad de género en particular son más bien resultado de una fusión de horizontes entre intérprete e interpretandum y entre cultura y naturaleza.

Por otro lado, el constructivismo butleriano no aclara las diferencias entre un cuerpo artificial y otro humano ¿Se vivirían ambos como cuerpos subjetivo-objetivos? Desde nuestro punto de vista, ignorando los significados no culturales del cuerpo, estamos aprobando teóricamente cualquier manipulación tecnológica de los mismos que sirva para hacer fluido el género. Esta prepotencia y este sueño de dominación se acercan peligrosamente a la tecnocracia que sólo consiente falsas libertades encadenadas a necesidades impuestas. $^{84}$

Los géneros no son, como parece pensar Butler, simples roles que puedan permutarse, sino que están inscritos en el cuerpo y ligados a un universo del que extraen toda su fuerza. Por eso, la idea de género es útil para comprender la subjetividad y la identidad, pero también lo es el cuerpo vivido en tanto identidad que nos abre a las diferencias. Éste rompe con la tradicional oposición naturaleza-cultura que fundamenta la dicotomía sexo-género. Desde él, entendemos la subjetividad imbricada con la objetividad y a la inversa, porque la persona está condicionada por la cultura y la sociedad, así como por

83 Cf. Butler, J., Gender Trouble. New-York: Routledge, 1990, p. 7.

84 Véase una reflexión más amplia sobre esto en mi artículo, "El cuerpo vivido como nudo de identidad y diferencias. Una alternativa al cuerpo objetivado", en Choza, J./Pintos, M.L., Antropología y ética ante los retos de la biotecnologia. Thémata. Revista de Filosofia 33 (2004), pp. 141-148. 
los objetos mundanos con los que forja sus experiencias y comportamientos sin perjuicio de que actúe y tome decisiones en relación (apropiadora o crítica) con estas determinaciones.

Frente a Butler, en la obra merleau-pontiana, hemos descubierto la necesidad de interconectar el sexo y el género. Sin embargo, este último no consiste, a nuestro modo de ver, en una mera cobertura abstracta y artificiosa de aquél, sino que ambos están en interacción dinámica. En otras palabras, lo que hay es un quiasmo entre el cuerpo en el mundo y la identidad social que ayuda a configurar la corporalidad. De ahí que, lejos de absolutizar el sexo o el género, Merleau-Ponty nos aliente a buscar una tercera vía entre constructivismo y esencialismo. Hemos defendido en este trabajo que esa tercera vía se halla en la continuación de la filosofía merleau-pontiana del cuerpo fenoménico, el cual va más allá del determinismo biológico y del relativismo cultural, porque pertenece a una situación natural-cultural y, por ello, no es ni el resultado de determinaciones esenciales ni una creación social ex nihilo. El cuerpo no es ni estrictamente natural ni complemente construido a voluntad; es el punto de enlace necesario con el mundo ¿Cómo compaginar esta reconceptualización y reivindicación de la naturaleza corporal evitando el esencialismo? Por ejemplo, recuperando modos de conocimiento sensibles devaluados por el logos instrumental dominante, maneras corporales de producir conocimientos prácticos, opuestas a las formas dualistas derivadas del cartesianismo que pretenden alcanzar la libertad en el espíritu como lo opuesto al cuerpo; buscando universales concretos o existenciales.

La concepción merleau-pontiana del cuerpo vivido y la centralidad de éste para la experiencia puede ayudarnos a vivir nuestro cuerpo como ser vertical o "Ser salvaje", 85 como motor y movimiento anclado en el suelo (Boden), que engloba todo lugar y lleva a todos los vivientes más allá de la nada. Esta reafirmación del cuerpo propio exige una autovaloración del mismo como unidad interior-exterior. La vivencia vertical del cuerpo es la base de la libertad y el origen inmanente de todas las trascendencias. Esta verticalidad permite a Merleau-Ponty tomar en cuenta la diferencia sexual sin reducirla a la objetividad del cuerpo, pero pensando la alteridad del otro a partir de su carne.

Desde sus orígenes, las filosofías feministas han tomado al cuerpo como tema, probablemente por haberlo considerado una pieza clave de la construcción socio-cultural del género. Aquí hemos insistido en la utilidad de la rehabilitación merleau-pontiana del cuerpo vivido o fenoménico, que no puede confundirse ni con el cuerpo objetivado ni con el biológico, como uno de los principales factores de construcción de la subjetividad y de la identidad. Hemos insistido, por otra parte, en que la experiencia vivida en la existencia encarnada 
permite superar el determinismo y la normativización a la que nos abocan las tesis constructivistas y salvar la libertad del sujeto.

Aunque la concepción procesual de la identidad en Merleau-Ponty anticipa el paradigma de la performatividad del género, hemos destacado sus raíces corporales sin confundir la identidad personal con la sexual y hemos subrayado que ambas no son simples productos del discurso. La fenomenología se remonta a la experiencia pre-predicativa y a la intención significativa que no puede venir por completo al lenguaje. No sólo los signos y símbolos tienen significado, sino también las acciones y la experiencia, que es el contexto de éstas. La cultura occidental ha culminado en un sofisticado orden simbólico sin percibir que éste siempre está encarnado y carece de significado si no es experimentado como expresión creadora.

La estrategia de pensar desde el cuerpo y de encarnar el lenguaje y la racionalidad tiene su raíz en Merleau-Ponty. En cambio, el postestructuralismo rechaza tanto la razón impuesta como la razón comprometida y autorizada. Aunque estemos de acuerdo con su deconstrucción de la primera, pensamos que no es aplicable a la segunda, la cual todavía está por hacer. La fenomenología puede ayudarnos a re-fundar esa racionalidad en su autocomprensión, bien entendido que ésta exige la crítica de sus usos. Esta tarea infinita requiere dejar de entender la racionalidad como el privilegio de un solo género, y afrontarla como una responsabilidad común. ${ }^{86}$

Por otro lado, las tendencias posrmodernas se han centrado en los discursos olvidando que éstos se fundan en el cuerpo, se reproducen con sus acciones y que, a su vez, el cuerpo es su producto. Por eso nos adherimos a las críticas de dichos movimientos que abandonan completamente la naturaleza a la hora de explicar el género, dejándolo al arbitrio de las producciones exclusivamente culturales de significado. ${ }^{87}$ En nuestra opinión, la estructura fenomenológica del cuerpo no depende sólo de lo que se ha decidido considerar significativo o del supuesto de que podamos construirlo o manipularlo a nuestro antojo. Los dualismos que le afectan y a los que toda su vida se enfrentó Merleau-Ponty, se encuentran tan enraizados que no pueden ser atribuidos únicamente a la nominación verbal.

En este sentido, nuestra tesis es que la mayor contribución de MerleauPonty al feminismo es su trascendencia de las dicotomías y, especialmente, de la que se ha erigido entre naturaleza y cultura, pero también la que separa la razón de la sensiblidad y hasta la razón teórica de la razón práctica. El feminismo necesita articular ambos polos de una nueva manera, sin perder de vista

${ }^{86} \mathrm{Cf}$. Husserl, E., Die Krisis der Europäischen Wissenschaften und die transzendentale Phänomenologie. Husserliana VI. The Hague: M. Nijhoff, 1976, pp. 272-273.

87 Un buen ejemplo de esas críticas, inspirado en Merleau-Ponty, es Bigwood, C., "Renaturalizing the Body (with the Help of Merleau-Ponty", en Welton, D. (ed.), Body and Flesh. A Philosophical Reader: Okford: Blackwell, 1998, pp. 99-111. 
el cuerpo o la experiencia vivida. El concepto central de la nueva ontología anti-dualista que Merleau-Ponty nos propone en sus últimos escritos, la Chair, deja de oponerlos y pasa a entenderlos como componentes inseparables del ser humanizado. La nueva ontología merleau-pontiana amplia los poderes motores del cuerpo, a las fuerzas centrípetas y centrífugas de la carne. De ese modo, la relación de ser del cuerpo con el mundo se afianza todavía más y se abre a los otros seres de carne sin la distancia horizontal que todavía instaura la relación cognitiva.

La dialéctica merleau-pontiana entre la naturaleza y la cultura permite re-naturalizar el cuerpo, aprehenderlo desde un punto de vista fenomenológico, no biológico, para poder comprender la identidad en el seno de las diferencias, incluida la identidad sexual sin negar su indeterminación ni su apertura a posibles variaciones socioculturales.

Es obvio que el cuerpo vivido no se reduce al sexo, sino que es "simbolismo natural", 88 tácito de indivisión o evidencia precientífica en la que se funda todo simbolismo y toda razón. Ya en la Fenomenología de la Percepción Merleau-Ponty decía que la fuente primera de toda elaboración simbólica era la corporeidad, en virtud de sus conductas ${ }^{89}$ que se sitúan entre la naturaleza y el lenguaje. El cuerpo es simbolismo no en el sentido de la representación, sino por expresar lo otro, por ser una entidad investida de libido para otros/otras y por ser expresión de introyecciones libidinales de lo otro en mí. ${ }^{90}$

La crítica feminista del dualismo sexual y de las desigualdades en razón del mismo necesita rememorar también el olvido patriarcal del ser y de la necesidad de una antropología y ontología abiertas al ser vertical, como lo es la endo-ontología merleau-pontiana fundada en el ser incorporado y situado. Superando las explicaciones estructuralistas de la conformación discursiva, esta ontología indirecta permite comprender por qué nuestros cuerpos son divergentes al mismo tiempo que se solapan. Pero la conciencia despierta de la filosofía no se queda en esa experiencia pre-reflexiva del quiasmo, sino que reflexiona sobre nuestros deseos y reconoce o rechaza las diferencias.

La fenomenología merleau-pontiana que quiere ser la filosofía de la no filosofía, el pensamiento de la no coincidencia, puede ayudar también a mantener alerta a la conciencia de un feminismo no dogmático que piense la dialéctica entre identidad y diferencias, entre aquello que no es común y lo que nos singulariza. Además, las mujeres necesitamos reconocimiento y protección de los derechos a las diferencias necesarias para el progreso de lo común ligadas a nuestros cuerpøs y a la configuración sociocultural de los mismos. En ese sentido, resulta necesaria una ética comprensiva de los poderes del cuerpo 
propio, de sus hábitos y de sus proyecciones o deseos que no presuponga la clausura de su normatịvización.

\section{RESUMEN}

En este trabajo hacemos balance del centenario de Merleau-Ponty y Simone de Beauvoir, celebrado en el 2008, poniendo de relieve la relación entre la Fenomenología de la percepción y El segundo Sexo y subrayando la importancia que ambas obras conceden al cuerpo vivido. Explicitamos por qué la fenomenología de la existencia merleau-pontiana permite comprender la experiencia vivida por las mujeres, así como sus posibles relaciones con el feminismo. Nos detenemos en las consecuencias para el mismo de la redefinición merleau-pontiana de la subjetividad y de la razón. Destacamos su crítica de los reduccionismos, tanto epistemológicos como ontológicos. Rebatimos ciertas acusaciones que las propias feministas dirigen a Merleau-Ponty. Para ello, recorremos la obra merleau-pontiana en busca de huellas de la mujer y las contextualizamos, a la vez que subrayamos la adhesión de este filósofo a las correcciones que M. Mead y M. Klein hicieron a la interpretación freudiana de la sexualidad. Estudiamos también su propia hermenéutica del psicoanálisis, completado con la fenomenología, destacando la contribución de la misma a la deconstrucción de los estereotipos sobre la feminidad. Defendemos finalmente la continuidad del feminismo de I.M. Young con la fenomenología de Merleau-Ponty, interpretamos las aportaciones de éste como correctivo a las tendencias postestructurales y al constructivismo de Butler y concluimos extrayendo las principales claves merleau-pontianas que consideramos productivas para el feminismo actual.

\footnotetext{
ABSTRACT

It is my contention that there is a significant relationship between "Phenomenology of Perception" (Merleau-Ponty) and "The Second Sex" (de Beauvoir). The two authors give great importance to the lived body (Leib), either from a neutral perspective, either from a perspective feminine. This key concept of the phenomenology allows us to understand the lived experience of women and their possible relationship with feminism. From this corporeal sense we analyze the Merleau-Pontinian redefinition of subjectivity and reason. We emphasize his criticism of reductionism, both epistemological as ontological. We refute certain feminists accusations against Merleau-Ponty. To do this, we study all his work in search of traces of women, we place them in context, while we study his own hermeneutics of psychoanalysis in order to highlight the contribution of it to the deconstruction of stereotypes about femininity. We conclude by showing the main keys of this phenomenology for the current feminist Philosophy.
} 
